\title{
The impact of COVID-19 pandemic and restriction measures on sexual behaviour, couple relationship and psychological well-being in Latvia
}

\author{
Ieva Briedite ${ }^{1,2}$, Anda Kivite-Urtane ${ }^{1}$, Gunta Lazdane ${ }^{1}$, Dace Rezeberga ${ }^{1}$, Inara Kantane ${ }^{1}$, Elizabete Pumpure ${ }^{1}$, Ieva Pitkevica ${ }^{1}$, Marta Laura \\ Gravina $^{1}$ and Darja Mihailova ${ }^{1}$ \\ ${ }^{1}$ Riga Stradins University, Latvia \\ ${ }^{2}$ Capital Clinic Riga, Latvia
}

\begin{abstract}
Purpose: Since the beginning of COVID-19 restrictions, almost all domains of people's lives have been affected, including couple and family relationships and sexual life. There are various factors that are likely to influence the partner availability, intimacy, emotional well-being, contraception access and interpersonal tension.

Materials and methods: Behavioural cross-sectional online survey (I-SHARE) combined with structured interviews with the aim to determine the impact of COVID-19 social restriction measures on sexual health and psychological well-being and behaviour was conducted.

Results and conclusions: Results showed increase of tension and its negative impact on frequency and satisfaction with sex life. Frequency of sexual intercourse decreased more for people who did not live with their partner. Increase of alcohol consumption and loss of job decreased satisfaction with sex life. Controversial data about contraception availability and intimate partner violence were obtained showing no impact in survey, but revealing contraception access restrictions and intimate partner violence increase during qualitative research interviews.
\end{abstract}

\section{Introduction}

Since March 11, 2020, when the World Health Organisation (WHO) declared the novel coronavirus disease pandemic, a significant proportion of the world population is either under complete lockdown or partial lockdown along with family or even unwanted company [1]. Almost all domains of lives have been affected and sexual life is not an exception. However, there is a dearth of studies assessing the impact of the crisis on sexual health of all including sexual and gender minority groups [2].

Cabinet of Ministers of the Republic of Latvia announced a state of emergency and introduced a number of restrictions from March 13 to June 9,2020 . Though numbers of COVID-19 cases were fast-rising worldwide, the rate of COVID-19 incidence and fatalities in Latvia till late September 2020 was significantly lower than in neighbouring countries and globally $[3,4]$.

To ensure that healthcare facilities will be able to manage predicted crisis of uncontrollable disease, elective surgeries and outpatient consultations were cancelled, making access to healthcare professionals less available. Online counselling was not available during the first months of the pandemic. Restrictions were related even to earlier scheduled outpatient services. Only the following health care services were provided starting from March 27, 2020: antenatal care, health services for patients with confirmed sexually transmitted diseases, HIV and with oncological diseases, while other services were postponed for unknown period. Services related to contraception and family planning were not included in the available healthcare services list [6].
The restrictions due to pandemic (social distancing, self-isolation), deferral of planned manipulations and outpatient counselling and undersupply of healthcare providers are just a few of causes that might result in reduced access to sexual and reproductive health (SRH) services $[7,8]$. Nevertheless, the possible fear of unknown consequences to their health, foetus $[9,10]$, fertility [11], maternity services [12], interaction with other infectious diseases and many more as well might be a reason people avoided visiting public places (including outpatient clinics, pharmacies) and limited their access to medication [13], contraceptive methods, antenatal care and testing of sexually transmitted and other infections.

There are various factors that are likely to influence the intimacy resulting in an alteration in sexual behaviours. The factors that may facilitate sexual intimacy are - increased time spent together, little opportunity for recreation, less work burden, less social or family obligations. Similarly, there are several factors that may adversely affect sexual life, such as more chance of interpersonal conflicts, stress, lack of privacy and medical issues. The net outcome in the sexual behaviours of an individual is the cumulative effect of facilitating and limiting factors. As the COVID-19 pandemic is evolving rapidly and the lockdown state is getting prolonged, understanding the changing pattern of sexual

${ }^{*}$ Correspondence to: Ieva Briedite, Department of Obstetrics and Gynaecology Dzirciema iela 16, Riga, Latvia, LV-1007, E-mail: Ieva.Briedite@rsu.lv

Key words: COVID-19, sexual health, sexual behaviour, relationship, intimate partner violence

Received: March 24, 2021; Accepted: April 16, 2021; Published: April 21, 2021 
behaviour may give some insight to the deviations of behaviour, so that possible remediation measures can be taken [14].

WHO has also identified that there are risks related to genderbased and domestic violence because of negative psychological effects of quarantine (post-traumatic stress symptoms, confusion and anger) $[15,16]$. A historical analysis of global epidemic response has described a toxic mix of blaming, exploitation of social divisions and government deployment of authority, with potential for social conflict and power imbalances [17].

\section{Aims}

The aims of the study were as follows:

1. To determine the impact of COVID-19 social restriction measures in Latvia on sexual health and behaviour;

2. To determine the impact of COVID-19 social restriction measures in Latvia on access to sexual health services;

3. To determine the impact of COVID-19 social restriction measures in Latvia on the psychological well-being and couple relationship;

4. To determine the impact of COVID-19 social restriction measures in Latvia on intimate partner violence (IPV).

\section{Materials and methods}

The study consists of the behavioural cross-sectional online survey with convenience sampling [18] combined with the qualitative research of structured interviews with people living with HIV, health care providers and leaders of governmental and non-governmental organizations (NGO) involved in SRH.

The survey items, methods and implementation guidance have been selected from a recent UNDP/UNFPA/UNICEF/WHO/World Bank Special Programme of Research, Development and Research Training in Human Reproduction (HRP) consensus meeting to develop a standardized survey instrument focused on SRH [19]. The survey development is partly based on existing questions and scales, and partly on newly developed questions. Academic Network for Sexual and Reproductive Health and Rights Policy (ANSER) [20] initiated quantitative International Sexual Health and Reproductive Health study (I-SHARE) including 30 countries [21]. ANSER network centrally programmed the self-administrated online survey questionnaire using Open Data Kit software (version 1.16) that could be completed through smartphones, tablets or computers. Translation to Latvian and Russian languages and local field testing was managed by authors.

Inclusion criteria for the survey included 18 years or older currently residing in Latvia and able to provide online informed consent. Standard fraud protection methods, including CAPTCHA and a measure to prevent more than one response from a single IP address were included.

Socio-demographics have been summarized by using descriptive statistics (distribution of frequencies, central tendencies) and the nonparametric tests have been used in analysis (Wilcoxon Sign Rank test, Chi-Square test, Fisher exact test). Data have been summarised and analysed by using MS Excel and IBM SPSS 26.0. The results have been defined as statistically significant if $p<0.05$. Study was approved by the Research Ethics Committee of Riga Stradins University.

\section{Results}

1173 people living in Latvia submitted an online survey. $82.4 \%$ of respondents were women, $17.4 \%$ men, $0.3 \%$ identified themselves as other sex. People who participated were 18 to 68 years old. $35.3 \%$ of responders were in the age group from 25 to 32 years, followed by the age group 18 to 24 years (24.5\%). Dominantly, $63 \%$ of responders lived in the capital of Latvia, Riga (Table 1). In $201956 \%$ of population of Latvia were living in the metropolitan area of the capital.

Besides results of the survey characterizing sociodemographic situation of responders, this article summarizes outcomes related to the following chapters of the survey: compliance with COVID-19 restrictions, number of questions were on couple and family relationships, sexual behaviour, access to condoms, access to contraceptives, and intimate partner violence. Most respondents (37.8\%) noted having sexual relations 2 to 3 times a week or 2 to 4 times a month (37.4\%). Much less had sex 4 or more times a week (14.3\%), or monthly or less $(9.3 \%)$. For $58.8 \%$ of respondents frequency of sexual relations during COVID-19 did not change, for $20.1 \%$ it decreased and for $21.2 \%$ increased comparing with the time before COVID-19 restrictions. No statistical difference was noted on the frequency of sexual relations between women and men before and during COVID-19 restrictions. The impact of COVID-19 restrictions on satisfaction with sex life was studied. Three months before COVID-19 restrictions, $81.9 \%$ responders were satisfied with their sex life, during COVID-19 restrictions it decreased to $75.9 \%$ of responders $(\mathrm{p}<0.01)$. Three months before restrictions $82.7 \%$ women were satisfied with sex life, during the time of restrictions $75.8 \%$ were satisfied $(\mathrm{p}<0.001)$. Changes in satisfaction with sex life among men were not statistically significant. Significant differences were noted between men and women on casual sexual relations: men were more likely than women to have casual sex before COVID-19 restrictions $(\mathrm{p}<0.001) .30 .6 \%$ men and $13.9 \%$ women have had casual sex once a month or less. $82.1 \%$ men and $91.1 \%$ women noted no change in casual sexual relations frequency during restrictions. People who were in relationship with a steady partner and lived together more often had sex in times of restrictions compared with people who did not live with a partner. The frequency

Table 1. Descriptive data of 1173 responders including sex, language, age group and place of residence

\begin{tabular}{|c|c|c|c|c|c|c|}
\hline \multirow{2}{*}{ Sex, $\%$} & Man & Woman & Other & & & \\
\hline & 17.4 & 82.4 & 0.3 & & & \\
\hline \multirow{2}{*}{ Language, $\%$} & Latvian & Russian & & & & \\
\hline & 83.2 & 16.8 & & & & \\
\hline & & & & & & \\
\hline \multirow{2}{*}{ Age group, $\%$} & $18-24$ & $25-32$ & $33-39$ & $40-47$ & $48-54$ & $>54$ \\
\hline & 24.5 & 35.3 & 18.2 & 11.9 & 5.6 & 4.5 \\
\hline \multirow{2}{*}{ Place of residence, $\%$} & Capital city & City & Remote/rural area & Suburb of city & Town & Other \\
\hline & 63.0 & 12.5 & 2.7 & 12.6 & 8.0 & 0.9 \\
\hline
\end{tabular}


of sexual intercourse decreased more for people who did not live with their partner $(\mathrm{p}=0.005)$. Respondents, who were legally married and lived together, were more satisfied with their sex life during restrictions than those in a relationship but not living together $(\mathrm{p}<0.001) .54 .9 \%$ of respondents did not have children, $16.2 \%$ had one child, $20.2 \%$ two, $7.1 \%$ three, $1.2 \%$ four and $0.3 \%$ had 5 children. People who did not have children more often were dissatisfied with their sex life during COVID-19 restrictions compared with people who had children, $27.2 \%$ vs. $20.2 \%$ accordingly ( $\mathrm{p}=0.002$ ).

Before COVID-19 pandemic, $40.6 \%$ watched pornography monthly or less, $18.4 \% 2$ to 4 times a month. Men more often watched pornography than women $(\mathrm{p}<0.001) .11 .3 \%$ of responders increased watching pornography during restrictions. Before COVID-19 30.3\% masturbated monthly or less, $25 \% 2$ to 4 times a month, $12.3 \% 2$ to 3 times a week and $6.7 \% 4$ or more times a week. Men masturbated more often than women $(\mathrm{p}<0.001) .13 .3 \%$ of responders increased masturbation during restrictions.

The COVID-19 pandemic changed the economic situation of many and it also affected satisfaction with sex life. Less satisfied with sex life were responders whose workload was reduced (20.5\%) and those, who lost job or business (21.2\%). Respondents rated their income on a scale from 1 to 10 where 1 indicated the lowest income group and 10 the highest income group. $53.9 \%$ of people from the low income group were not satisfied with their sex life. In contrast, only $7.7 \%$ of people with high income were not satisfied with their sex life ( $\mathrm{p}=0.001)$. $46.9 \%$ of respondents who fully lost income, $27 \%$ who partially lost income during COVID-19 restrictions were dissatisfied with their sex life. However, $21.4 \%$ of respondents who indicated that their income level did not change were not satisfied with their sex life. People who increased alcohol consumption during COVID-19 restrictions were less satisfied with their sex life $(\mathrm{p}<0.001)$. This association was observed especially among women $(\mathrm{p}=0.009)$.

For most of women (96.9\%), COVID-19 restrictions did not affect the availability of contraception. Factors that stopped $1.6 \%$ of women from obtaining contraception were as follows: for $36.4 \%$ doctor / health professional unavailability, for $22.7 \%$ fear to get COVID- 19 if they would go to the doctor / health centre, for $13.6 \%$ long queues at health centre / clinic or unavailability at a certain time, for $9.1 \%$ the chosen method of contraception were not in stock and for $4.5 \%$ no transport was available. $57.7 \%$ of women did not seek or obtain contraceptive services during COVID-19 restrictions, others turned to a doctor / nurse at a hospital (5.2\%), online services (5.6\%), telephone services (3.1\%), community health centre (4.8\%), pharmacy (4.8\%), family physician (2.9\%). Male condoms were the most commonly used method of contraception (used by $39.4 \%$ of women). Access for condoms during restrictions was difficult for $1.4 \%$ of respondents. Qualitative research results revealed more challenges in relation to the access to contraception: ' $I$ would like to say that accessibility to contraception was certainly more restricted than before, because scheduled doctor's appointments were not allowed. Women, who had stable, long-term relationships with their doctor were able to resolve this issue. Essentially only condom accessibility was not limited, but partially, depending on if one was afraid to go to the pharmacy, because it was recommended to stay at home,' a president of a professional association. 'We cannot think of a healthy family life if a woman does not have the opportunity to live her sexual life fully using the contraceptive that is most suitable for her,' said the head of NGO.

$97 \%$ of respondents were in a relationship. From those who were not in a relationship, $42.9 \%$ noted that their relationship ended during COVID-19 restrictions, for $21.4 \%$ after restrictions. $17.9 \%$ said that the end of their relationship was precipitated by COVID-19 social distancing measures, $17.9 \%$ were not sure about the cause. $70.5 \%$ responders received the same amount of emotional support during COVID-19, 8.8\% less support, 20.7\% more support than before restrictions. Respondents rated their overall mental health: $48.1 \%$ as good, $23 \%$ as very good, $18.7 \%$ as fair, $6.9 \%$ as excellent and $3.3 \%$ as poor. $28.5 \%$ of respondents noted that they more frequently got angry with a slight provocation. During COVID-19 restrictions, $29.8 \%$ of respondents noted an increase in tension in the relationship with a steady partner. Results showed a correlation: as tension increased, dissatisfaction with sex life increased $(\mathrm{p}<0.001)$ and sex life frequency decreased $(\mathrm{p}<0.001)$.

Responders were asked if their partner has insulted them or made them feel bad about themselves. The answer was positive for $13.5 \%$ once and $11 \%$ multiple times three months before and $11.3 \%$ once and 9.2\% multiple times in times of COVID-19. For both men $(\mathrm{p}=0.018)$ and women $(\mathrm{p}<0.001)$ insults were less often during COVID-19. $4.6 \%$ have been slapped, punched, hit, kicked, choked or things were thrown at them three months before restrictions versus $2.5 \%$ during COVID-19. 2.4\% responders before and 1.8\% during restrictions were physically forced to have sexual intercourse. $1.2 \%$ responders before and $1.6 \%$ responders during restrictions noted they had unwanted sexual intercourse because they were afraid of what their partner might do to them (Figure 1). $12.6 \%$ talked with a friend, $6.1 \%$ with a relative, $6.5 \%$ with another person, but $70.6 \%$ did not talk to anybody about the violence they experienced during COVID-19. Analysis of the reports of the qualitative part of the study presented different results. As nongovernmental organisations which dealt with violence were closed during COVID-19 restrictions, assistance needed for victims of violence was difficult to provide. 'It was a very difficult time. It was a time when public authorities had to be persuaded not to cut a service that was not already fully funded', said the head of NGO. 'People who asked for help were twice as much as before COVID-19 restrictions. Cases of violence were extremely cruel, including sexual violence and even the death of a woman, she added. Observations from a medical doctor specialized in sexology about the times of restrictions 'We received information about emotional abuse, family disagreements, that people in a relationship had disagreements that resulted in divorce.

\section{Discussion}

Study showed that in majority of cases (58.8\%) frequency of sexual relations during COVID-19 did not change. There was no difference between women and men, but dissatisfaction with sex life increased ( $18.1 \%$ vs. $24.1 \%)$, with statistical significance only in women. Similar

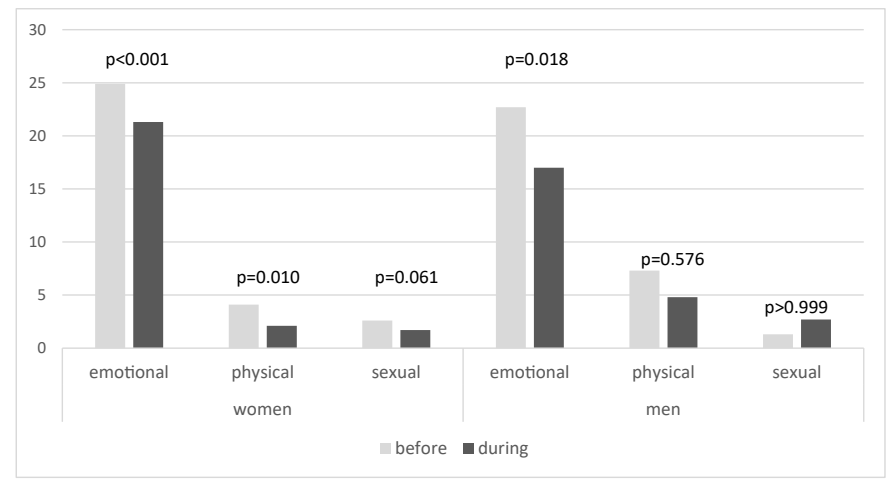

Figure 1. Comparison of changes in violence among women and men before and during COVID-19 restrictions, \% 
decrease of sexual function among women has been observed in other studies [22]. Participants rated their overall mental health as good (48.1\%), but noted that they got angry with a slight provocation more frequently during restrictions. During COVID-19 restrictions, $29.8 \%$ of respondents noted an increase in tension in the relationship with their regular partner. Results showed a negative correlation between partnership tension and satisfaction with sex life, that is in line with previously published data $[23,24]$.

For $96.9 \%$ of women from survey COVID-19 restrictions did not affect the availability of contraception, which could be because condoms were the most commonly used method of contraception and still freely available. Our study did not show that women decided to discontinue contraception by themselves as it has been concluded in other studies [25], but qualitative research results provided information regarding barriers in accessing contraception during the COVID-19 related restrictions.

People who were in a stable relationship with a regular partner and lived together, more often had sexual relations during COVID-19 restrictions compared with those who did not live together with a partner. One of the possible explanations may be linked to the fact that single men and women were trying to avoid COVID-19 infection avoiding physical contact [26].

Despite the increase of awareness about the impact of smoking and alcohol consumption during the COVID-19 pandemic by experts [27] some part of population increased alcohol consumption. Participants of our study who increased alcohol consumption during COVID-19 restrictions were less satisfied with their sex life. This was especially relevant to women. The research data on alcohol use and satisfaction with sex life in women is limited, but in line with our findings [28].

"Stay-at-home" orders, intended to protect the public and to prevent further spread of infection, but left many IPV victims trapped with their abusers [29]. Experts providing assistance to the victims of IPV in Latvia were aware that the rates of IPV had not decreased, but rather victims were unable to safely connect with services and NGO support groups were not available. Most people who experience IPV don't seek help. There may be barriers of reporting IPV during the pandemic. The way in which police reports is filed varies country from country, with some offering online options and others requiring in-person visits [30]. Our study showed decrease in emotional abuse from intimate partner during restrictions among survey participants and $70.6 \%$ of those, who experienced IPV, did not report to anyone during COVID-19. But results of the qualitative part of the study differed and confirmed the increase of the number cases of IPV and level of cruelty during the COVID-19 restrictions in Latvia. This controversial aspect of our study indicates that online surveys may not reach all groups of society to show representable picture of all population, including potentially isolated victims of violence.

The main limitations of the study were the relatively low number of participants, convenience sampling method which probably did not reach all specific risk groups and self-reported answers with possible interpretation variations. But results showed good general insight of the problems and provided information useful for building recommendations for SRHR policy makers to impact future decisions and improve outcomes.

Further prospective studies with a larger number of participants and qualitative research of specific target groups would be important to confirm our results and to understand possible reasons of some results related to contraception and intimate partner violence.

\section{Conclusions}

Frequency of sexual relations during COVID-19 in Latvia did not change, but increase in sex life dissatisfaction was noted. The frequency of sexual intercourse decreased more for people who did not live with their partner. Respondents living together with partner were more satisfied with their sex life during restrictions than those in a relationship but not living together. People, especially women, who increased alcohol consumption during COVID-19 restrictions were less satisfied with their sex life. Survey showed no effect on availability of contraception, but qualitative part revealed restricted access to certain methods. As relationship tension increased, sex life frequency decreased and dissatisfaction with sex life increased. Surprisingly, but survey showed decrease in partner emotional violence and no changes in other domains of intimate partner violence, but interviews discovered significant increase of all kinds of violence. Combination of qualitative and quantitative research revealed significant advantages of improving data collection and disclosing real situation. More in depth research of the impact of COVID-19 restrictions in Latvia is needed.

\section{Acknowledgement}

This study was done in the context of the I-SHARE study (International Sexual Health and Reproductive Health), which examines the impact of the COVID-19 crisis on sexual and reproductive health in diverse low-income, middle-income, and high-income countries. The full list of consortium members and their roles can be found here https://ishare.web.unc.edu

\section{Funding}

National Research Programme to Lessen the Effects of COVID-19 Project Nr. VPP-COVID-2020/1-0011 "Impact of COVID-19 on health care system and public health in Latvia; ways in preparing health sector for future epidemics"

\section{Conflict of interest}

The authors report no conflicts of interest

\section{References}

1. who.int [Internet]. Coronavirus disease (COVID- 19) situation report as of 14th March [cited 2020 Nov 20]. Available from: https:/www.who.int/emergencies/diseases/novelcoronavirus-2019/situation-reports/.

2. Hafi B, Uvais NA, Rabeeh V, Arjun PC, Tonjam R, et al. (2020) Effect of COVID-19 lockdown on sexual minorities: A pilot survey study in India. Ind J Health Sex Cul 6: 60-65.

3. bnn-news.com [Internet]. Latvia's COVID-19 success puzzles Lithuanian pundits, draws global praises [cited 2020 Nov 20]. Available from: https://bnn-news.com/latvias-covid-19-success-puzzles-lithuanian-pundits-draws-global-praises-212874.

4. spkc.gov.lv [Internet]. COVID-19 in Latvia [cited 2020 Nov 20]. Available from https://www.spkc.gov.lv/lv/aktualitates-par-covid-19.

5. infogram.com [Internet]. Statistics of COVID-19 in Latvia [cited 2020 Nov 20] Available from: https://infogram.com/c19-izplatiba-latvija-2020-1h7v4pzlzlnj6k0.

6. m.likumi.lv [Internet]. Restrictions of health care services during COVID-19 emergency, law nr. 59 [cited 2020 Nov 20]. Available from: https://m.likumi.lv/doc.php?id=313 481\&fbclid=IwAR3q_3nXF87F3C53-98pgbwDG51XsEu1uj9Ln139HtDeRrPmCdSMwZIDbo.

7. Tang K, Gaoshan J, Ahonsi B, Ali M, Bonet M, et al. (2020) Sexual and reproductive health (SRH): a key issue in the emergency response to the coronavirus disease (COVID- 19) outbreak. Reproductive Health 17, Article number: 59.

8. who.int [Internet]. COVID-19: Operational guidance for maintaining essential health services during an outbreak. Interim guidance: 25 March 2020 [cited 2020 Nov 20]. Available from: https://www.who.int/emergencies/diseases/novel-coronavirus-2019/ technical-guidance/maintaining-essential-health-services-and-systems. 
9. Chen H, Guo J, Wang C, Luo F, Yu X, et al. (2020) Clinical characteristics and intrauterine vertical transmission potential of COVID-19 infection in nine pregnant women: a retrospective review of medical records. Lancet 395: 10226. [Crossref]

10. cnr.cn [Internet]. Neonates tested SARS-CoV-2 positive 30 hours after birth [cited 2020 Nov 30]. Available from: http://www.cnr.cn/hubei/yuanchuang/20200205/ t20200205_524961963.shtml.

11. Fan C, Li K, Ding Y, Lu WL, Wang J (2020) ACE2 Expression in kidney and testis may cause kidney and testis damage after 2019-nCoV infection. medRxiv.

12. Wong SF, Chow KM, Leung TN, Ng WF, Ng TK, et al. (2004) Pregnancy and perinatal outcomes of women with severe acute respiratory syndrome. Am J Obstet Gynecol 191: 292-297. [Crossref]

13. unaids.org [Internet]. UNAIDS And China working together during the COVID-19 outbreak to ensure that people living with HIV continue to get treatment [cited 2020 Dec 15]. Available from: https://www.unaids.org/en/resources/presscentre/ pressreleaseandstatementarchive/2020/february/20200218_china_covid19.

14. Sharma P, Kabir R (2020) Does COVID-19 pandemic affect sexual behaviour? A crosssectional, cross-national online survey. Psychiatry Res 289: 113050. [Crossref]

15. Brooks SK, Webster RK, Smith LE, Woodland L, Wessely S, et al. (2020) The psychological impact of quarantine and how to reduce it: rapid review of the evidence. Lancet 395: 10227. [Crossref]

16. Chynoweth SK, Amsalu R, Casey SE, McGinn T (2018) Implementing sexual and reproductive health care in humanitarian crises. Lancet 391: 1770-1771. [Crossref]

17. Hussein J (2020) COVID-19: What implications for sexual and reproductive health and rights globally? Sex Reprod Health Matters 28: 1. [Crossref]

18. who.int [Internet]. The WHO Strategic Approach to strengthening sexual and reproductive health policies and programmes, 2007 [cited 2020 Dec 15]. Available from: https://www.who.int/reproductivehealth/publications/strategic approach/ RHR_07.7/en/.

19. Kpokiri E (2020) Implementation Considerations for Population-Based Sexual and Reproductive Health Research. Nairobi, Kenya: Africa Population Health Research Council, 2020.
20. ugent.be [Internet]. Academic Network for Sexual and Reproductive Health and Rights Policy [cited 2021 Jan 15]. Available from: https://www.ugent.be/anser/en.

21. ishare.web.unc.edu [Internet]. International Sexual Health and Reproductive Health study [cited 2021 Jan 15]. Available from: https://ishare.web.unc.edu/.

22. Schiavi MC, Spina V, Zullo MA, Colagiovanni V, Luffarelli P, et al. (2020) Love in the time of COVID-19: Sexual function and quality of life analysis during the social distancing measures in a group of Italian reproductive-age women. $J$ Sex Med 17: 14071413. [Crossref]

23. Bodenmann G, Ledermann T, Nelson Bradbury TN (2007) Stress, sex, and satisfaction in marriage. Personal Relationships 14: 551-569.

24. Tavares IM, Schlagintweit EH, Nobre PJ, Rosen NO (2019) Sexual well-being and perceived stress in couples transitioning to parenthood: A dyadic analysis. Int J Clin Health Psychol 19: 198-208. [Crossref]

25. Caruso S, Rapisarda AMC, Minona P (2020) Sexual activity and contraceptive use during social distancing and self-isolation in the COVID-19 pandemic. Eur $J$ Contracept Reprod Health Care 25: 445-448. [Crossref]

26. Ibarra FP, Mehrad M, Mauro MD, Godoy MFP, Cruz EG, et al. (2020) Impact of the COVID-19 pandemic on the sexual behavior of the population. The vision of the east and the west. Int Braz J Urol 46: 104-112. [Crossref]

27. Mahanty C, Kumar R, Mishra BJ (2020) Analyses the effects of COVID-19 outbreak on human sexual behaviour using ordinary least-squares based multivariate logistic regression. Qual Quant 18: 1-21. [Crossref]

28. George WH (2019) Alcohol and sexual health behavior: "What We Know and How We Know It". J Sex Res 56: 409-424.

29. theguardian.com [Internet]. In quarantine with an abuser: surge in domestic violence reports linked to coronavirus, April 3,2020 [cited 2021 Jan 20]. Available from: https:/ www.theguardian.com/us-news/2020/apr/03/coronavirus-quarantine-abuse-domesticviolence.

30. Evans ML, Lindauer M, Farrell ME (2020) A pandemic within a pandemic - Intimate partner violence during Covid-19. N Engl J Med 383: 2302-2304. [Crossref]

Copyright: (C2021 Briedite I. This is an open-access article distributed under the terms of the Creative Commons Attribution License, which permits unrestricted use, distribution, and reproduction in any medium, provided the original author and source are credited. 